\title{
Improving security of autologous hematopoietic stem cell transplant in patients with light-chain amyloidosis
}

\author{
Gonzalo Gutiérrez-García $\mathbb{1}^{1,2,3,4,5}$ - María Teresa Cibeira ${ }^{2,3,4,5} \cdot$ Montserrat Rovira ${ }^{1,2,3,4,5}$. \\ Carlos Fernández de Larrea ${ }^{2,3,4,5} \cdot$ Natalia Tovar ${ }^{2,3,4,5} \cdot$ Luis Gerardo Rodríguez-Lobato $\oplus^{1,2,3,4,5} \cdot$ Laura Rosiñol ${ }^{1,2,3,4,5}$. \\ Pedro Marín ${ }^{1,2,3,4,5}$ • Julio Solano-Vega ${ }^{1}$ - María Suárez-Lledó ${ }^{1,2,3,4,5}$. Alex Bataller (iD ${ }^{1,2,3,4,5}$. \\ María Teresa Solano ${ }^{1,2,3,4,5}$ - Noemí de Llobet ${ }^{1} \cdot$ Ariadna Domenech $^{1} \cdot$ Nuria Borràs $^{1} \cdot$ Miquel Lozano $^{3,4,5}$. \\ Joan Cid ${ }^{3,4,5}$ - Carmen Martínez ${ }^{1,2,3,4,5}$ - Álvaro Urbano-Ispizua 1,2,3,4,5 • Jordi Esteve ${ }^{1,2,3,4,5}$ - Enric Carreras ${ }^{6}$. \\ Francesc Fernández-Avilés ${ }^{1,2,3,4,5}$ • Joan Bladéé,3,4,5
}

Received: 13 November 2018 / Revised: 2 January 2019 / Accepted: 4 January 2019 / Published online: 21 January 2019

C Springer Nature Limited 2019

\begin{abstract}
Autologous stem cell transplant (ASCT) has demonstrated to be an effective treatment for patients with light-chain (AL) amyloidosis. However, a high transplant-related mortality (TRM) rate was reported in previous series of patients and questioned the role of transplant in this disease. Recently, experienced groups have shown a significant TRM decrease that has been attributed to an accurate selection of patients. Moreover, application of several supportive measures has decreased toxicity over amyloid-involved organs. We analyzed a series of 66 patients with AL amyloidosis, who underwent ASCT at a single institution and evaluated the impact of these measures beyond patient selection. Four temporary groups were established: group-A (non-selection plus post-transplant G-CSF use) with 29 patients, group-B (selection) with 13, group-C (selection and G-CSF avoidance) with 14, and group-D (selection, G-CSF avoidance and corticosteroid's prophylaxis) with 10. A decreasing TRM was observed over time from group-A (38\%), to group-D (0\%); $p=0.02$. We also observed a progressive increase of three-year OS from $62 \%$ in group-A to $100 \%$ in group-D; $p=0.049$. On the multivariate analysis, cardiac involvement was the only independent predictor of survival. Therefore, tailored selection policy together with transplant supportive measures have allowed ASCT to be a safe procedure in AL amyloidosis.
\end{abstract}

These authors contributed equally: Gonzalo Gutiérrez-García, María Teresa Cibeira

Gonzalo Gutiérrez-García

gonguti@clinic.cat

1 Bone Marrow Transplant Unit, Department of Hematology, Hospital Clínic of Barcelona, Barcelona, Spain

2 Amyloidosis and Multiple Myeloma Unit, Department of Hematology, Hospital Clínic of Barcelona, Barcelona, Spain

3 Department of Hemotherapy and Hemostasis, Hospital Clínic of Barcelona, Barcelona, Spain

4 University of Barcelona, Barcelona, Spain

5 Institut de Recerca Biomèdica August Pi i Sunyer, Barcelona, Spain

6 Barcelona Endothelium Team (BET), Josep Carreras Leukemia Research Institute, Barcelona, Spain

\section{Introduction}

Immunoglobulin light-chain (AL) amyloidosis is a plasma cell disorder characterized by deposition of misfolded monoclonal light chains in tissues resulting in dysfunction of involved organs, such as the heart, kidney, or liver [1-3]. The prognosis is poor, especially in patients with cardiac involvement [4]. Treatment relies on the clonal plasma cells control in order to decrease amyloidogenic light-chain deposition and to avoid organ dysfunction. Historically, oral melphalan in combination with corticosteroids demonstrated anti-plasma cell activity, leading to hematologic and organ responses and improving the outcome of patients with this disease [5, 6]. Nonetheless, the long-term use of alkylating drugs such as melphalan could be associated with the development of myelodysplastic syndromes [7]. In this setting, high-dose melphalan followed by autologous stem cell transplant (ASCT) resulted in high rates of durable hematologic and organ responses [8-12] and became the 
standard therapy in younger patients with $\mathrm{AL}$ amyloidosis. However, this procedure was associated with high toxicity and transplant-related mortality (TRM) up to $20-25 \%$ in early 2000s [12-15]. Consequently, the role of ASCT in this disease was questioned. During the last decade, different efforts to improve the outcome of patients with $\mathrm{AL}$ amyloidosis undergoing transplant have decreased the current TRM to 2-5\% in experienced centers [16-19]. Based on these results, high-dose melphalan followed by ASCT is still the cornerstone in the treatment of selected patients [19, 20], despite the introduction of novel agents, such as proteasome inhibitors (PI) and immunomodulatory drugs (IMiDs). The accurate selection of transplant candidates and the expertise of transplanting teams are the crucial factors to decrease TRM that has been demonstrated in several publications $[18,19,21]$. Moreover, the application of several supportive measures to avoid toxicity of the procedure over amyloid-involved organs makes this modality of transplant completely different compared with other monoclonal gammopathies, such as multiple myeloma (MM) [7]. Thus, several measures such as mobilization under strict control in order to minimize the inflammatory effects of high-dose granulocyte colony-stimulating factor [G-CSF] (fluid retention, non-cardiogenic pulmonary edema, and cardiac arrhythmias), avoidance of G-CSF after stem cell infusion (SCI) as well as prophylaxis with corticosteroids to decrease the risk of engraftment syndrome and, finally, specific hemostatic measures to decrease bleeding complications have been introduced in the last decade [22-32].

With this background, we retrospectively analyzed a series of patients with AL amyloidosis undergoing ASCT at a single institution over a 20 -years period. We focused on a number of supportive measures applied to the procedure over time and patient's selection policy in order to assess their impact on the outcome.

\section{Patients and methods}

Sixty-six patients diagnosed with biopsy-proven systemic AL amyloidosis received an ASCT at our institution between November 1997 and June 2017. Data regarding patients' characteristics, stem cell transplant, and subsequent outcomes were collected. We used the hematopoietic cell transplantation comorbidity index (HCT-CI) based on the criteria index reported by Sorror et al. [33, 34]. Organ involvement and response criteria were defined according to the international consensus criteria [35, 36]. The prognostic risk stratification was established according to 2004 and 2012 Mayo Clinic staging systems [37, 38]. In order to decrease TRM associated with ASCT for AL amyloidosis, different supportive measures were set up over the study period. First of all stem cell mobilization was performed with GCS-F (Filgrastim ${ }^{\oplus}$, Amgen, $8 \mu \mathrm{g} / \mathrm{kg} / 12 \mathrm{~h}$ ) as an inpatient procedure in all cases, while in those with heart involvement and/or previous significant comorbidity, the apheresis and optionally the stem cell infusion (SCI) were performed in the intensive care unit (ICU). Since 2005, mouth local cryotherapy is applied with the aim to reduce the incidence of oral mucositis. Stem cells infusion is performed by peripheral venipuncture instead of central catheter in patients with heart involvement or arrhythmia. Administration of intravenous (IV) tranexamic acid $(10 \mathrm{mg} /$ $\mathrm{kg}$ t.i.d.) during thrombocytopenia below $50 \times 10^{9} / \mathrm{L}$, prophylactic platelet transfusion when platelet count drops below $30 \times 10^{9} / \mathrm{L}$ and IV nutritional support in patients with clinical gastrointestinal amyloid involvement are all measures aimed to avoid hemorrhagic complications. Moreover, administration of IV albumin ( $20 \mathrm{~g}$, b.i.d.) when serum level is below $30 \mathrm{~g} / \mathrm{L}$ and accurate control of liquids are always performed to ensure a neutral balance.

From 2006, an accurate patients' selection policy has been applied with the following exclusion criteria: age over 70 years (patients from 66 to 70 years old are individually discussed), performance status (ECOG) over 2 (ECOG 3 only acceptable if due to gastrointestinal or peripheral neuropathic involvement), severe heart involvement (NYHA functional class III-IV, ejection fraction below $50 \%$, severe arrhythmias, and/or pleural effusion), clinically significant or symptomatic involvement of three or more major organs (taking into account the heart, kidney, liver, and gastrointestinal), spirometry and diffusion capacity of the lungs for carbon monoxide (DLCO) below 50\%, and hyperbilirubinemia over $3 \mathrm{mg} / \mathrm{dL}$. In patients with serum creatinine over $3 \mathrm{mg} / \mathrm{dL}$, candidacy for transplant was individualized taking into account age, hematopoietic cell transplantation comorbidity index (HCT-CI) and number of organs involved.

From January 2011, our Bone Marrow Transplant Unit discontinued the administration of G-CSF after ASCT in patients with $\mathrm{AL}$ amyloidosis to prevent engraftment syndrome (ES). Before that date, patients used to receive GCSF ( $5 \mathrm{mcg} / \mathrm{kg}$ daily) from day +7 after SCI until an absolute neutrophil count (ANC) above $0.5 \times 10^{9} / \mathrm{L}$ for three consecutive days was reached.

In January 2014, primary prophylaxis with corticosteroids for ES prevention was implemented. Since then, patients received IV methylprednisolone at a dose of 0.5 $\mathrm{mg} / \mathrm{kg}$ daily from day +7 after transplant until their ANC reached $0.5 \times 10^{9} / \mathrm{L}$ during 3 consecutive days. All patients received also antimicrobial prophylaxis with quinolone, fluconazole, acyclovir (as long as herpes serology was positive), and aerosolized pentamidine. At the onset of the first neutropenic fever over $38^{\circ} \mathrm{C}$, all patients had central and peripheral blood cultures, urine culture, and a chest Xray examination was performed with appropriate additional 
Table 1 Clinical criteria for engraftment syndrome diagnosis

Maolino criteria for engraftment syndrome

Non-infectious fever plus one of the following:

Skin rash

Pulmonary infiltrates

Diarrhea, starting $24 \mathrm{~h}$ before or at any time after the first appearance of neutrophils. At least two episodes of liquid depositions/day without microbiological documentation of infection.

evaluations as clinically indicated (e.g., chest CT), and institutional supportive care protocol was applied in these cases. To detect patients with a possible ES, we analyzed all non-infectious fever episodes developed within 10 days of engraftment (starting 3 days before $\mathrm{ANC} \geq 0.5 \times 10^{9} / \mathrm{L}$ ) and the Maiolino diagnostic criteria detailed in Table 1 were applied [39]. Non-infectious fever was defined as a new fever $\left(>38^{\circ} \mathrm{C}\right)$ without clinical or microbiological documentation or response to antimicrobials. Pulmonary infiltrates were documented using X-ray or computed tomography and were considered ES if there were no signs of infection, cardiac failure, or pulmonary embolism. Skin rash was defined as maculo-papular exanthema mimicking acute GVHD involving $>25 \%$ of body surface area. Weight gain was accepted when it was $>2.5 \%$ of the basal. Diarrhea was defined as at least two episodes of liquid depositions per day without microbiological documentation of infection. All patients diagnosed with ES received treatment with methilprednisolone at a dose of $1 \mathrm{mg} / \mathrm{kg}$ twice a day for 3 days and then it was tapered over 7 to 8 days.

\section{Statistical analysis}

A descriptive statistical analysis was performed. Median value and range were used for continuous variables. Frequency and percentage were used for categorical variables. Group comparisons were done by chi-square test and Fisher exact test. Logistic regression analysis was performed by backward stepwise (Wald) method [40]. Outcomes analyzed included TRM rate, progression-free survival (PFS), and overall survival (OS). Estimates of outcomes were reported as probabilities with $95 \% \mathrm{CI}$. The incidence of TRM at 30-days, 100 days, and 1-year after SCI were calculated by Gray's method [41]. The probability of survival was calculated with the Kaplan-Meier estimator, and survival curves were compared with the log-rank test. The multivariate analysis was performed with a Cox proportional hazards model, including a Cox with time-varying covariate for the post-ASCT hematologic and organ response analysis. The assumption of proportional hazards was tested for each variable and they were adjusted by stratification. Potential interaction between the main effect and all other significant risk factors were tested. The threshold for statistical significance was defined as a twotailed $p<0.05$. All computations were made using the statistical packages SPSS version 25 and R version 3.4.1 [42].

\section{Results}

The median age of the series was 58 years (range, 34-71), and the male/female distribution was 32/34. Forty-seven patients $(71 \%)$ had HCT-CI score over 2. Thirty-seven patients $(56 \%)$ underwent ASCT upfront, while the remaining 29 (44\%) received previous therapy, which was mainly bortezomib based (15 patients). Among those patients who received pre-transplant treatment, 18 of them (62\%) achieved a hematologic response, including 15 partial responses (PR, 52\%) and 3 complete responses (CR, $10 \%)$. Moreover, $11(38 \%)$ of these 29 previously treated patients had achieved an organ response before transplant. Stem cell source was peripheral blood in all cases after mobilization with G-CSF, and two of them $(3 \%)$ received also plerixafor. The median CD34+cells infused was $3.03 \times 10^{6} / \mathrm{kg}$ (range, 1.8-10.5). All patients received melphalan as conditioning chemotherapy at a dose of $200 \mathrm{mg} / \mathrm{m}^{2}$ (80\% of them) or $140 \mathrm{mg} / \mathrm{m}^{2}(20 \%)$, most of them depending on renal function. The baseline characteristics of patients and transplant procedure are shown in Table 2. At the time of this analysis, the median follow-up was 10.3 years $(95 \% \mathrm{CI}: 9.3-11.3)$ for the entire cohort and 11.5 years (range, 10.2-12.9 years) for alive patients.

\section{Transplant-related mortality (TRM)}

For the whole series, mortality rate at 30-days and 100 days after SCI was $11 \%$ (7 patients) and $21 \%$ (14 patients), respectively. The cause of death was ES in eight patients (57\%), arrhythmia during first week after transplant in four (29\%), splenic rupture in one (7\%), and Pseudomonas aeruginosa bacteremia in the remaining patient $(7 \%)$. The significant variables associated with TRM were: HCT-CI $\geq$ 3, 14 patients $(30 \%), p=0.007$; number of involved organs $\geq 3,7$ patients $(39 \%), p=0.03$; cardiac involvement, $11(31 \%), p=0.04$; non-strict selection policy, $11(38 \%)$, $p=0.003$; use of G-CSF after SCI, 13 (31\%), $p=0.01$; and non-primary prophylaxis with corticosteroids, 14 (25\%), $p=0.04$. We did not find any correlation between TRM and age, pre-transplant treatment, and dose of conditioning chemotherapy. In this sense, we established four temporary evolutionary groups according to main measures applied from the start of the AL amyloidosis bone marrow program in 1997 and throughout the last two decades: Group-A (1997-2005, non-strict patient selection and use of G-CSF) with 29 patients (44\%), group-B (2006-2010, strict patient selection policy and use of G-CSF) with 13 patients $(20 \%)$, 
Table 2 Features of the patients, disease and transplant measures

\begin{tabular}{|c|c|}
\hline Characteristic & $\begin{array}{l}\text { All patients } \\
N=66\end{array}$ \\
\hline \multicolumn{2}{|l|}{ Age (years) } \\
\hline Median (range) & $57.7(34-71)$ \\
\hline \multicolumn{2}{|l|}{ Age, $n(\%)$} \\
\hline$<60$ & $46(70)$ \\
\hline$\geq 60$ & $20(30)$ \\
\hline \multicolumn{2}{|l|}{ Sex, $n(\%)$} \\
\hline Female & $34(51.5)$ \\
\hline Male & $32(48.5)$ \\
\hline \multicolumn{2}{|l|}{ HCT-CI score, $n(\%)$} \\
\hline$\leq 2$ & $19(29)$ \\
\hline$\geq 3$ & $47(71)$ \\
\hline \multicolumn{2}{|l|}{ Bone marrow plasma cells, $n(\%)$} \\
\hline$<10$ & $49(74)$ \\
\hline$\geq 10$ & $17(26)$ \\
\hline \multicolumn{2}{|l|}{ Light chain, $n(\%)$} \\
\hline Lambda & $51(77)$ \\
\hline Kappa & $15(23)$ \\
\hline \multicolumn{2}{|l|}{ Number of organs involved, $n(\%)$} \\
\hline$\leq 2$ & $48(73)$ \\
\hline$\geq 3$ & $18(27)$ \\
\hline Cardiac involvement, $n(\%)$ & $36(54.5)$ \\
\hline \multicolumn{2}{|l|}{ Stage (available in 25 patients), $n(\%)$} \\
\hline 1 & $6(24)$ \\
\hline 2 & $9(36)$ \\
\hline 3 & $7(28)$ \\
\hline 4 & $3(12)$ \\
\hline \multicolumn{2}{|l|}{ Pre-transplant treatment, $n(\%)$} \\
\hline Untreated & $37(56)$ \\
\hline Melphalan or cyclophosphamide based & $14(21.5)$ \\
\hline Bortezomib based & $15(22.5)$ \\
\hline \multicolumn{2}{|l|}{ Hematologic pre-transplant response, $n(\%)^{\mathrm{a}}$} \\
\hline $\mathrm{CR}$ & $3(5)$ \\
\hline PR & $14(21)$ \\
\hline PD & $49(74)$ \\
\hline \multicolumn{2}{|l|}{ Organic pre-transplant response, $n(\%)^{\mathrm{a}}$} \\
\hline No response & $18(62)$ \\
\hline Response & $11(38)$ \\
\hline \multicolumn{2}{|l|}{ Mobilization, $n(\%)$} \\
\hline G-CSF & $64(97)$ \\
\hline G-CSF plus plerixafor & $2(3)$ \\
\hline \multicolumn{2}{|l|}{$\mathrm{CD} 34+/ \mathrm{kg}$ cell infused } \\
\hline Median (range) & $3.0(1.8-10.5)$ \\
\hline \multicolumn{2}{|l|}{ Conditioning regimen, $n(\%)$} \\
\hline Melphalan $200 \mathrm{mg} / \mathrm{m}^{2}$ & $53(80)$ \\
\hline Melphalan $140 \mathrm{mg} / \mathrm{m}^{2}$ & $13(20)$ \\
\hline Strict selection policy, $n(\%)$ & $37(56)$ \\
\hline
\end{tabular}

Table 2 (continued)

\begin{tabular}{lc}
\hline Characteristic & $\begin{array}{l}\text { All patients } \\
N=66\end{array}$ \\
\hline G-CSF after SCT, $n(\%)$ & $24(36)$ \\
Prophylaxis with corticosteroids, $n(\%)$ & $10(15)$ \\
\hline
\end{tabular}

$C R$ complete response, $V G P R$ very good partial response, $P R$ partial response, $P D$ progression disease

${ }^{a}$ Analyzed in 29 pre-transplant treated patients

group-C (2011-2013, strict patient selection and G-CSF avoidance after SCI) with 14 patients $(21 \%)$ and group-D (2014-2017, strict patient selection, G-CSF avoidance after SCI and corticosteroid prophylaxis to prevent ES) with 10 patients $(15 \%)$. The incidence of neutropenic fever, ES, microbiologically documented infection. and other variables according to different temporary subgroups are detailed in Table 3. At the multivariate analysis, the only significant variables related to TRM were HCT-CI $\geq 3$ ( $p=0.007$, HR 7.1) and temporary evolutionary groups [TRM at 100 days: group-A (38\%), group-B (15\%), group-C (8\%), group-D $(0 \%)] ; p=0.02$, HR 9.5). These data are represented in Fig. 1 and Table 3.

\section{Post-transplant hematologic and organ response}

Hematologic and organ responses were evaluable in 52 patients alive (79\%) at 6 months after transplant. Regarding hematologic response, 29 patients $(56 \%)$ achieved a CR, 14 patients (27\%) obtained a PR, and 9 patients (17\%) did not respond. In the univariate analysis, the only significant variable associated with achievement of hematologic CR was pre-transplant treatment with bortezomib [pre-transplant bortezomib, $12(75 \%)$ vs. non pre-transplant bortezomib, 17 (34\%), $p=0.003$ ]. Regarding organ response, 37 (71\%) patients obtained response in at least one involved organ while 15 patients (29\%) did not achieve any organ response. Besides the fact that hematologic response is essential in order to obtain an organ response, no other significant variable with impact in organ response was found. A comparison between hematologic and organ response rates before and after ASCT is detailed in Fig. 2.

\section{Progression-free survival (PFS) and overall survival (OS)}

On an intention-to-treat analysis, the median PFS of all 66 patients was 4.1 years (95\% CI, 2.5-5.7 years), and the median OS was 10.3 years (95\% CI, 9.2-11.5 years) (Fig. 3). Among the 52 evaluable patients for response at 6 months after transplant, neither PFS nor OS were significantly longer for those who achieved a hematologic CR compared with those who did not. In the univariate analysis, 
Table 3 The main characteristics of patients according to temporary evolutionary groups

\begin{tabular}{|c|c|c|c|c|c|}
\hline$N=66$ & $\begin{array}{l}\text { Group-A } \\
N=29(44 \%)\end{array}$ & $\begin{array}{l}\text { Group-B } \\
N=13(20 \%)\end{array}$ & $\begin{array}{l}\text { Group-C } \\
N=14(21 \%)\end{array}$ & $\begin{array}{l}\text { Group-D } \\
N=10(15 \%)\end{array}$ & $p$ \\
\hline \multicolumn{6}{|l|}{ Age } \\
\hline$\geq 60$ years & $8(28)$ & $6(46)$ & $4(29)$ & $2(20)$ & 0.5 \\
\hline \multicolumn{6}{|l|}{ Sex } \\
\hline Male & $14(48)$ & $6(46)$ & $8(57)$ & $4(40)$ & 0.8 \\
\hline HCT-CI $\geq 3$ & $22(76)$ & $11(85)$ & $10(71)$ & $4(40)$ & 0.1 \\
\hline Cardiac involvement, $n(\%)$ & $18(62)$ & $7(54)$ & $6(43)$ & $5(50)$ & 0.6 \\
\hline Organs involved $\geq 3, n(\%)$ & $12(41)$ & $3(23)$ & $1(7)$ & $2(20)$ & 0.1 \\
\hline $\mathrm{BM}$ plasma cells $\geq 10, n(\%)$ & $12(41)$ & $1(8)$ & $2(14)$ & $2(20)$ & 0.07 \\
\hline \multicolumn{6}{|l|}{$\mathrm{CD} 34+/ \mathrm{kg}$ cell infused } \\
\hline Median (range) & $3(1.8-10.5)$ & $3(2.3-5.1)$ & $2.7(2-8.9)$ & $4.4(2.5-6.1)$ & 0.2 \\
\hline \multicolumn{6}{|l|}{ Neutrophils $\leq 0.5 \times 10^{9} / \mathrm{L}$} \\
\hline Median (days) & $7(6-10)$ & $6.5(5-7)$ & $10(7-12)$ & $6.5(3-10)$ & 0.4 \\
\hline \multicolumn{6}{|l|}{ Platelets $\leq 20 \times 10^{9} / \mathrm{L}$} \\
\hline Median (days) & $9(5-12)$ & $5(2-5)$ & $4(2-6)$ & $3(1-5)$ & 0.02 \\
\hline Neutropenic fever, $n(\%)$ & $24(83)$ & $12(92)$ & $9(64)$ & $4(40)$ & 0.02 \\
\hline Microbiological isolation, $n(\%)$ & $11(38)$ & $5(39)$ & $2(14)$ & $1(10)$ & 0.2 \\
\hline Engraftment syndrome, $n(\%)$ & $22(76)$ & $10(77)$ & $7(50)$ & $2(20)$ & 0.008 \\
\hline 100-days TRM & $11(38)$ & $2(15)$ & $1(8)$ & $0(0)$ & 0.02 \\
\hline
\end{tabular}

*Groups:

- Group-A (1997-2005): non-strict selection policy, use of post-transplant G-CSF, and not primary prophylaxis with corticosteroids

- Group-B (2006-2010): application of strict selection policy, use of post-transplant G-CSF, and not primary prophylaxis with corticosteroids

- Group-C (2011-2013): application of strict selection policy, post-transplant G-CSF avoidance, and not primary corticosteroids prophylaxis

- Group-D (2014-2017): application of strict selection policy, post-transplant G-CSF avoidance, and use of primary corticosteroids prophylaxis the variables with significant impact on 3 -years OS were: HCT-CI $(\leq 2,93 \%$ vs. $\geq 3,70 \% ; p=0.04)$, cardiac involvement (not involved, $90 \%$ vs. involved, $62 \% ; p=0.01$ ), and temporary evolutionary groups [group-A $(62 \%)$, group-B (76\%), group-C (84\%), group-D (100\%); $p=0.04$ ] (Fig. 4). In the multivariate analysis, the only variable with significant impact on OS was cardiac involvement $(p=0.02$; HR 2.7).

\section{Discussion}

Autologous stem cell transplantation has demonstrated to be an effective treatment option for patients with AL amyloidosis, able to obtain high hematologic and organ response rates and, most importantly, durable responses [8-12]. In this sense, long-term survival even over 10 or 15 years after transplant has been reported, being significantly longer than that obtained in patients with MM [43]. Although these results have established ASCT as the standard therapy for younger patients with $\mathrm{AL}$ amyloidosis, its role has been controversial due to a high TRM up to $24 \%$ reported in the prospective phase III trial by Intergroupe Francophone du Myélome [12]. More recently, large series of patients undergoing ASCT in experienced centers have shown a dramatic improvement in their outcomes mainly due to a drop in early mortality rate $[16,18,19,21]$. Since cardiac involvement is the main predictor of survival in this disease, a strict patient selection policy has obviously been crucial to achieve a reduction of TRM. Moreover, the severe toxicity that patients may experience over amyloid-involved organs has led to set up a number of supportive measures [7, 25]. The evolution of these supportive measures, based in the progressive acquisition of experience by transplanting teams during the last decade, has made this procedure completely different compared with that applied to other monoclonal gammopathies, such as MM [7]. In our series, both patient selection and supportive measures have allowed to significantly improve the safety of ASCT in AL amyloidosis. In this sense, actions such as mobilization in admission regimen, peripheral SC infusion in patients with cardiac involvement, and strict hemostatic control have 

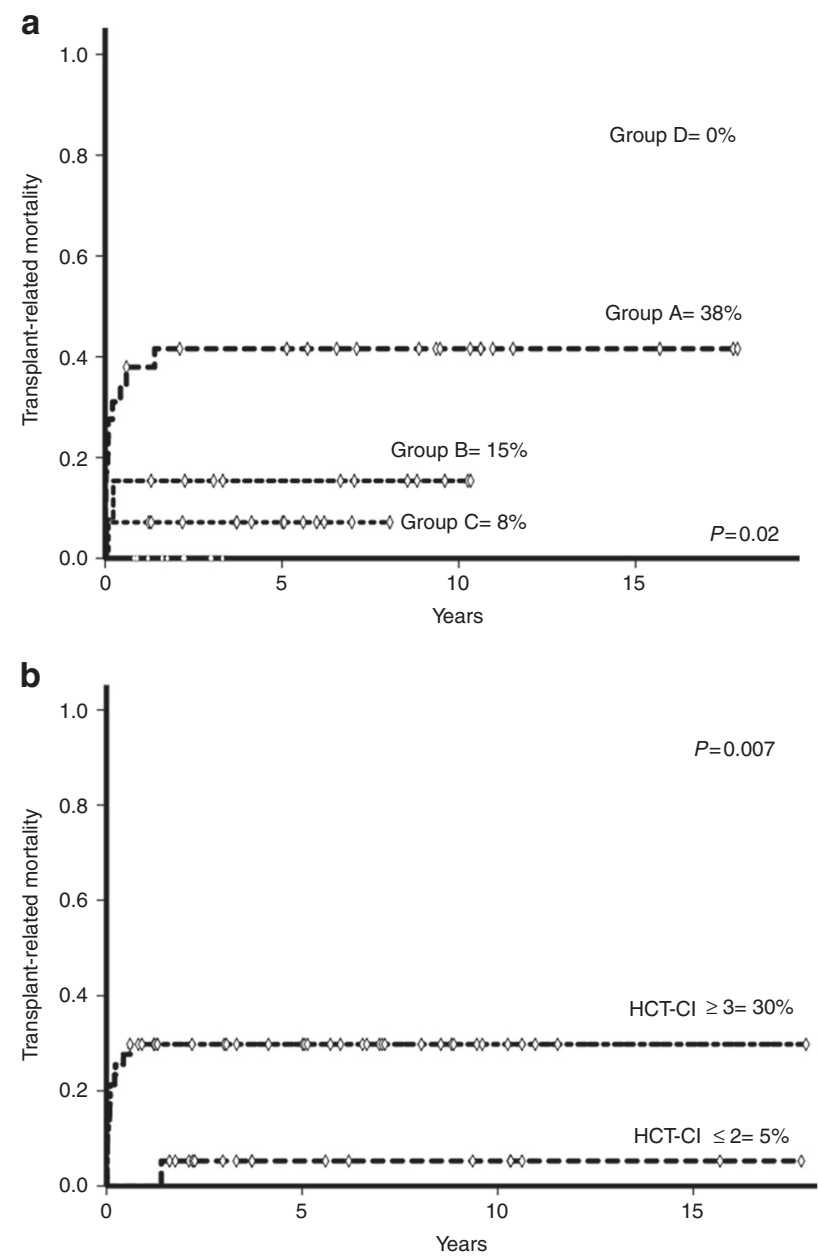

Fig. 1 Transplant-related mortality (TRM) according to temporary evolutionary groups (a) and hematologic comorbidity index (HCT-CI) (b). *Groups: Group-A (1997-2005): non-strict selection policy, use of post-transplant G-CSF, and not primary prophylaxis with corticosteroids. Group-B (2006-2010): application of strict selection policy, use of post-transplant G-CSF, and not primary prophylaxis with corticosteroids. Group-C (2011-2013): application of strict selection policy, post-transplant G-CSF avoidance, and not primary corticosteroids prophylaxis. Group-D (2014-2017): application of strict selection policy, post-transplant G-CSF avoidance, and use of primary corticosteroids prophylaxis. ${ }^{*}$ HCT-CI hematopoietic cell transplantation comorbidity index

contributed to reduce early mortality minimizing the occurrence of cardiac arrhythmias, sudden cardiac death, and gastrointestinal bleeding. Particularly, TRM was high in our series during the first period (group-A-1997-2005$38 \%$ ) and significantly decreased when a strict patient selection policy was set up (group-B, 15\%). The main event associated with TRM was ES, with an incidence of $76 \%$ and $77 \%$ in groups A and B, respectively. For this reason, in 2011 we decided to avoid G-CSF administration after SCI and, since 2014, we have established prophylaxis with methylprednisolone in an attempt to reduce the ES incidence. Consequently, a decrease of TRM rate in the second
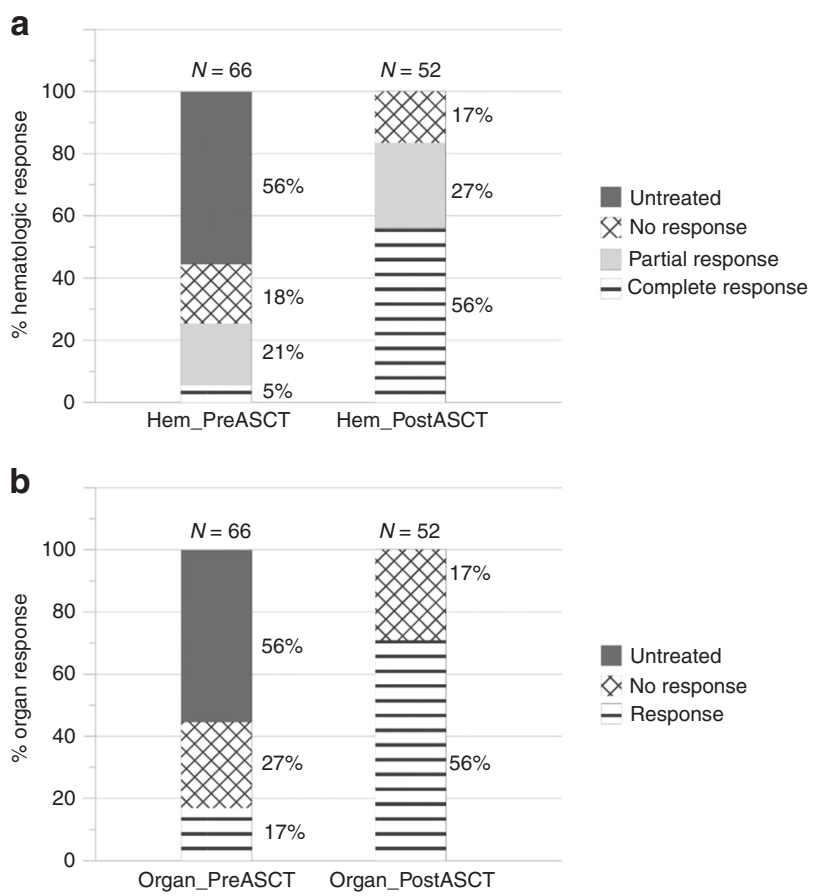

Fig. 2 Hematologic response (a) and organ response (b) according to pre- and post-transplant status

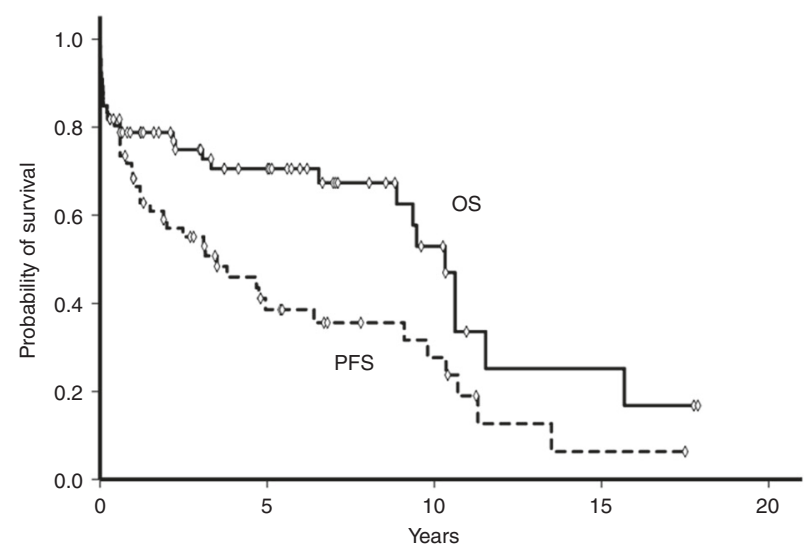

Fig. 3 Overall survival and progression-free survival of the series

decade was achieved (group-C, $8 \%$ and group-D, 0\%) resulting in a significant survival prolongation (3-years OS: group-A, $62 \%$, group-B, $76 \%$, group-C, $84 \%$ and group-D, $100 \% ; p=0.049)$. Of interest, we did not observe association between melphalan dose and TRM or survival, which might be explained by the relatively small number of patients receiving reduced melphalan dose. However, the HCT-CI over 2 was a predictor of TRM, and OS reflecting the impact of a suitable candidate in the outcome of the ASCT.

In agreement with other studies, our results highlight the importance of cardiac involvement as the most important predictor of survival. Regarding CR achievement, one of the prognostic factors associated was pre-transplant 

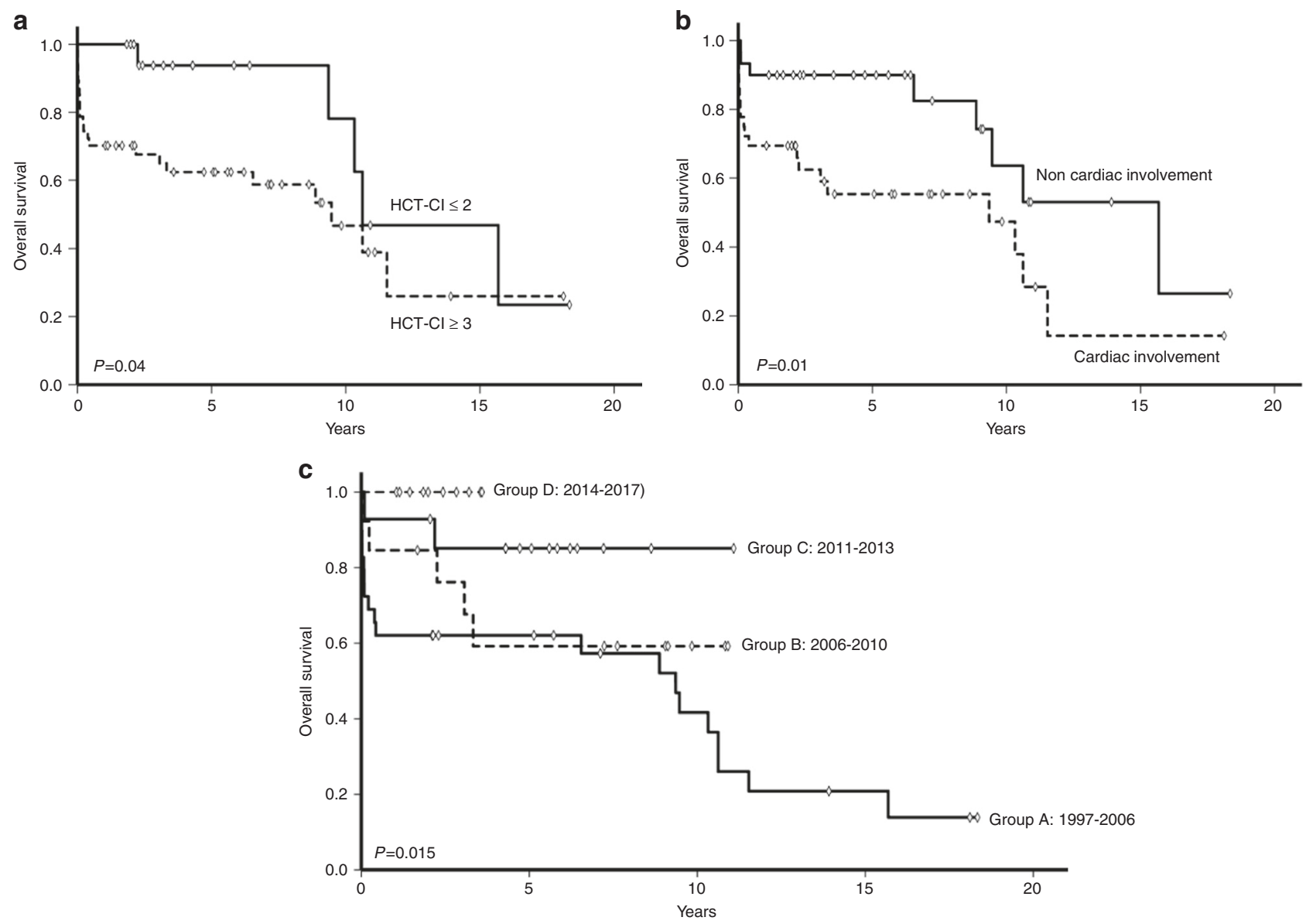

Fig. 4 Overall survival according to HCT comorbidity index (HCTCI) (a), cardiac involvement (b), and temporary evolutionary groups (c). *Groups: Group-A (1997-2005): non-strict selection policy, use of post-transplant G-CSF, and not primary prophylaxis with corticosteroids. Group-B (2006-2010): application of strict selection policy, use of post-transplant G-CSF, and not primary prophylaxis with

treatment with bortezomib. However, it must be noted that the greatest number of patients receiving a bortezomibbased induction were those transplanted during the second decade of the study period (groups C and D), and the role of pre-transplant induction therapy has not yet been set up. The lack of association between hematologic CR achievement and survival might also be explained by the small size of the series and the impact of other variables.

In summary, our data demonstrate a significant improvement of outcomes after ASCT in AL amyloidosis in terms of TRM reduction and survival (PFS and OS) based on the evolution of the several support measures (avoiding G-CSF, use of parenteral nutrition, stem cell infusion by peripheral catheter, use of prophylaxis with corticosteroids to decrease inflammatory events) mainly due to the reduction of early mortality reflected in specific groups over time (A, B, C, and D). The incorporation of transplant supportive measures, particularly those aimed to reduce ES, are crucial corticosteroids. Group-C (2011-2013): application of strict selection policy, post-transplant G-CSF avoidance, and not primary corticosteroids prophylaxis. Group-D (2014-2017): application of strict selection policy, post-transplant G-CSF avoidance, and use of primary corticosteroids prophylaxis

for a safer ASCT in patients with AL amyloidosis together with a strict patients selection policy.

Acknowledgements This work has been supported in part by grants PI12/01290 and PI16/0423 from Instituto de Salud Carlos III and Fondo Europeo de Desarrollo Regional (FEDER), and 2017SGR-792 from AGAUR (Generalitat de Catalunya).

\section{Compliance with ethical standards}

Conflict of interest Gonzalo Gutiérrez-García: honoraria from Gilead. María Teresa Cibeira: honoraria from Janssen, Celgene, and Amgen. Carlos Fernández de Larrea: honoraria from Janssen, Celgene, and Amgen; advisory boards: Janssen, Celgene, and Amgen; grants from: Janssen, Celgene, Amgen, and Takeda. Laura Rosiñol: honoraria from Janssen, Celgene, Amgen, and Takeda. The remaining authors declare that they have no conflict of interest.

Publisher's note: Springer Nature remains neutral with regard to jurisdictional claims in published maps and institutional affiliations. 


\section{References}

1. Kyle RA. Amyloidosis. Circulation. 1995;91:1269-71.

2. Merlini G, Bellotti V. Molecular mechanisms of amyloidosis. N Engl J Med. 2003;349:583-96. https://doi.org/10.1056/NEJMra 023144.

3. Kyle RA, Gertz MA. Primary systemic amyloidosis: clinical and laboratory features in 474 cases. Semin Hematol. 1995;32:45-59.

4. Dispenzieri A, Gertz MA, Kyle RA, Lacy MQ, Burritt MF, Therneau TM, et al. Prognostication of survival using cardiac troponins and N-terminal pro-brain natriuretic peptide in patients with primary systemic amyloidosis undergoing peripheral blood stem cell transplantation. Blood. 2004;104:1881-7. https://doi. org/10.1182/blood-2004-01-0390.

5. Palladini G, Perfetti V, Obici L, Caccialanza R, Semino A, Adami $\mathrm{F}$, et al. Association of melphalan and high-dose dexamethasone is effective and well tolerated in patients with AL (primary) amyloidosis who are ineligible for stem cell transplantation. Blood. 2004;103:2936-8. https://doi.org/10.1182/blood-2003-08-2788.

6. Kyle RA, Gertz MA, Greipp PR, Witzig TE, Lust JA, Lacy MQ, et al. A trial of three regimens for primary amyloidosis: colchicine alone, melphalan and prednisone, and melphalan, prednisone, and colchicine. N Engl J Med. 1997;336:1202-7. https://doi.org/10. 1056/NEJM199704243361702.

7. Sher T, Gertz MA. Stem cell transplantation for immunoglobulin light chain amyloidosis. Curr Probl Cancer. 2017;41:129-37. https://doi.org/10.1016/j.currproblcancer.2017.03.001.

8. Comenzo RL, Vosburgh E, Simms RW, Bergethon P, Sarnacki D, Finn K, et al. Dose-intensive melphalan with blood stem cell support for the treatment of AL amyloidosis: one-year follow-up in five patients. Blood. 1996;88:2801-6.

9. Comenzo RL, Gertz MA. Autologous stem cell transplantation for primary systemic amyloidosis. Blood. 2002;99:4276-82.

10. Skinner M, Sanchorawala V, Seldin DC, Dember LM, Falk RH, Berk JL, et al. High-dose melphalan and autologous stem-cell transplantation in patients with AL amyloidosis: an 8-year study. Ann Intern Med. 2004;140:85-93.

11. Moreau P, Leblond V, Bourquelot P, Facon T, Huynh A, Caillot $\mathrm{D}$, et al. Prognostic factors for survival and response after highdose therapy and autologous stem cell transplantation in systemic AL amyloidosis: a report on 21 patients. $\mathrm{Br} \mathrm{J}$ Haematol. 1998;101:766-9.

12. Jaccard A, Moreau P, Leblond V, Leleu X, Benboubker L, Hermine $\mathrm{O}$, et al. High-dose melphalan versus melphalan plus dexamethasone for AL amyloidosis. N Engl J Med. 2007;357:108393. https://doi.org/10.1056/NEJMoa070484.

13. Dispenzieri A, Kyle RA, Lacy MQ, Therneau TM, Larson DR, Plevak MF, et al. Superior survival in primary systemic amyloidosis patients undergoing peripheral blood stem cell transplantation: a case-control study. Blood. 2004;103:3960-3. https://doi. org/10.1182/blood-2003-12-4192.

14. Perfetti V, Siena S, Palladini G, Bregni M, Di Nicola M, Obici L, et al. Long-term results of a risk-adapted approach to melphalan conditioning in autologous peripheral blood stem cell transplantation for primary (AL) amyloidosis. Haematologica. 2006;91:1635-43.

15. Sanchorawala V, Skinner M, Quillen K, Finn KT, Doros G, Seldin DC. Long-term outcome of patients with AL amyloidosis treated with high-dose melphalan and stem-cell transplantation. Blood. 2007;110:3561-3. https://doi.org/10.1182/blood-2007-07-099481.

16. Cibeira MT, Sanchorawala V, Seldin DC, Quillen K, Berk JL, Dember LM, et al. Outcome of AL amyloidosis after high-dose melphalan and autologous stem cell transplantation: long-term results in a series of 421 patients. Blood. 2011;118:4346-52. https://doi.org/10.1182/blood-2011-01-330738.
17. Rosengren S, Mellqvist UH, Nahi H, Forsberg K, Lenhoff S, Stromberg O, et al. Outcome of AL amyloidosis after high-dose melphalan and autologous stem cell transplantation in Sweden, long-term results from all patients treated in 1994-2009. Bone Marrow Transplant. 2016;51:1569-72. https://doi.org/10.1038/ bmt.2016.249.

18. D'Souza A, Dispenzieri A, Wirk B, Zhang MJ, Huang J, Gertz MA, et al. Improved Outcomes After Autologous Hematopoietic Cell Transplantation for Light Chain Amyloidosis: A Center for International Blood and Marrow Transplant Research Study. J Clin Oncol. 2015;33:3741-9. https://doi.org/10.1200/JCO.2015. 62.4015 .

19. Sidiqi MH, Aljama MA, Buadi FK, Warsame RM, Lacy MQ, Dispenzieri A et al. Stem Cell Transplantation for Light Chain Amyloidosis: Decreased Early Mortality Over Time. J Clin Oncol 2018: JCO2017769554. e-pub ahead of print, 21 March 2018; https://doi.org/10.1200/JCO.2017.76.9554

20. Sanchorawala V, Brauneis D, Shelton AC, Lo S, Sun F, Sloan JM, et al. Induction Therapy with Bortezomib Followed by Bortezomib-High Dose Melphalan and Stem Cell Transplantation for Light Chain Amyloidosis: Results of a Prospective Clinical Trial. Biol Blood Marrow Transplant. 2015;21:1445-51. https:// doi.org/10.1016/j.bbmt.2015.04.001.

21. Gertz MA, Lacy MQ, Dispenzieri A, Kumar SK, Dingli D, Leung $\mathrm{N}$, et al. Refinement in patient selection to reduce treatmentrelated mortality from autologous stem cell transplantation in amyloidosis. Bone Marrow Transplant. 2013;48:557-61. https:// doi.org/10.1038/bmt.2012.170.

22. Leung N, Leung TR, Cha SS, Dispenzieri A, Lacy MQ, Gertz MA. Excessive fluid accumulation during stem cell mobilization: a novel prognostic factor of first-year survival after stem cell transplantation in AL amyloidosis patients. Blood. 2005;106:3353-7. https://doi.org/10.1182/blood-2005-03-1206.

23. Kumar S, Dispenzieri A, Lacy MQ, Litzow MR, Gertz MA. High incidence of gastrointestinal tract bleeding after autologous stem cell transplant for primary systemic amyloidosis. Bone Marrow Transplant. 2001;28:381-5. https://doi.org/10.1038/sj.bmt. 1703155.

24. Hoshino Y, Hatake K, Muroi K, Tsunoda S, Suzuki T, Miwa A, et al. Bleeding tendency caused by the deposit of amyloid substance in the perivascular region. Intern Med. 1993;32:879-81.

25. Yeh JC, Shank BR, Milton DR, Qazilbash MH. Adverse Prognostic Factors for Morbidity and Mortality During Peripheral Blood Stem Cell Mobilization in Patients with Light Chain Amyloidosis. Biol Blood Marrow Transplant. 2018;24:815-9. https://doi.org/10.1016/j.bbmt.2017.11.040.

26. Choufani EB, Sanchorawala V, Ernst T, Quillen K, Skinner M, Wright DG, et al. Acquired factor $\mathrm{X}$ deficiency in patients with amyloid light-chain amyloidosis: incidence, bleeding manifestations, and response to high-dose chemotherapy. Blood. 2001;97:1885-7.

27. Falk RH, Rubinow A, Cohen AS. Cardiac arrhythmias in systemic amyloidosis: correlation with echocardiographic abnormalities. J Am Coll Cardiol. 1984;3:107-13.

28. Carreras E, Fernandez-Aviles F, Silva L, Guerrero M, Fernandez de Larrea C, Martinez C, et al. Engraftment syndrome after autoSCT: analysis of diagnostic criteria and risk factors in a large series from a single center. Bone Marrow Transplant. 2010;45:1417-22. https://doi.org/10.1038/bmt.2009.363

29. Akasheh M, Eastwood D, Vesole DH. Engraftment syndrome after autologous hematopoietic stem cell transplant supported by granulocyte-colony-stimulating factor (G-CSF) versus granulocyte-macrophage colony-stimulating factor (GM-CSF). Bone Marrow Transplant. 2003;31:113-6. https://doi.org/10. 1038/sj.bmt. 1703784 
30. Kawano C, Muroi K, Kuribara R, Matsumoto Y, Ohtsuki T, Hatake K, et al. Engraftment syndrome after autologous peripheral blood stem cell transplantation with high numbers of peripheral blood stem cells followed by granulocyte colony-stimulating factor administration. Bone Marrow Transplant. 2000;25:228-9. https://doi.org/10.1038/sj.bmt.1702110

31. Irazabal MV, Eirin A, Gertz MA, Dispenzieri A, Kumar S, Buadi FK, et al. Acute kidney injury during leukocyte engraftment after autologous stem cell transplantation in patients with light-chain amyloidosis. Am J Hematol. 2012;87:51-54. https://doi.org/10. 1002/ajh.22202

32. Mossad S, Kalaycio M, Sobecks R, Pohlman B, Andresen S, Avery $\mathrm{R}$, et al. Steroids prevent engraftment syndrome after autologous hematopoietic stem cell transplantation without increasing the risk of infection. Bone Marrow Transplant. 2005;35:375-81. https://doi.org/10.1038/sj.bmt. 1704769

33. Sorror ML, Maris MB, Storb R, Baron F, Sandmaier BM, Maloney DG, et al. Hematopoietic cell transplantation (HCT)-specific comorbidity index: a new tool for risk assessment before allogeneic HCT. Blood. 2005;106:2912-9. https://doi.org/10.1182/ blood-2005-05-2004

34. Labonte L, Iqbal T, Zaidi MA, McDiarmid SA, Huebsch LB, Tay $\mathrm{J}$, et al. Utility of comorbidity assessment in predicting transplantation-related toxicity following autologous hematopoietic stem cell transplantation for multiple myeloma. Biol Blood Marrow Transplant. 2008;14:1039-44. https://doi.org/10.1016/j. bbmt.2008.06.019

35. Gertz MA, Comenzo R, Falk RH, Fermand JP, Hazenberg BP, Hawkins PN, et al. Definition of organ involvement and treatment response in immunoglobulin light chain amyloidosis (AL): a consensus opinion from the 10th International Symposium on Amyloid and Amyloidosis, Tours, France, 18-22 April 2004. Am J Hematol. 2005;79:319-28. https://doi.org/10.1002/ajh.20381.

36. Palladini G, Dispenzieri A, Gertz MA, Kumar S, Wechalekar A, Hawkins PN, et al. New criteria for response to treatment in immunoglobulin light chain amyloidosis based on free light chain measurement and cardiac biomarkers: impact on survival outcomes. J Clin Oncol. 2012;30:4541-9. https://doi.org/10.1200/ JCO.2011.37.7614.

37. Dispenzieri A, Gertz MA, Kyle RA, Lacy MQ, Burritt MF, Therneau TM, et al. Serum cardiac troponins and N-terminal probrain natriuretic peptide: a staging system for primary systemic amyloidosis. J Clin Oncol. 2004;22:3751-7. https://doi.org/10. 1200/JCO.2004.03.029.

38. Kumar S, Dispenzieri A, Lacy MQ, Hayman SR, Buadi FK, Colby C, et al. Revised prognostic staging system for light chain amyloidosis incorporating cardiac biomarkers and serum free light chain measurements. J Clin Oncol. 2012;30:989-95. https://doi. org/10.1200/JCO.2011.38.5724.

39. Maiolino A, Biasoli I, Lima J, Portugal AC, Pulcheri W, Nucci M. Engraftment syndrome following autologous hematopoietic stem cell transplantation: definition of diagnostic criteria. Bone Marrow Transplant. 2003;31:393-7. https://doi.org/10.1038/sj.bmt. 1703855

40. Scrucca L, Santucci A, Aversa F. Regression modeling of competing risk using R: an in depth guide for clinicians. Bone Marrow Transplant. 2010;45:1388-95. https://doi.org/10.1038/bmt.2009. 359

41. Scrucca L, Santucci A, Aversa F. Competing risk analysis using $\mathrm{R}$ : an easy guide for clinicians. Bone Marrow Transplant. 2007;40:381-7. https://doi.org/10.1038/sj.bmt.1705727

42. Delgado J, Pereira A, Villamor N, Lopez-Guillermo A, Rozman C. Survival analysis in hematologic malignancies: recommendations for clinicians. Haematologica. 2014;99:1410-20. https://doi. org/10.3324/haematol.2013.100784

43. Dispenzieri A, Seenithamby K, Lacy MQ, Kumar SK, Buadi FK, Hayman SR, et al. Patients with immunoglobulin light chain amyloidosis undergoing autologous stem cell transplantation have superior outcomes compared with patients with multiple myeloma: a retrospective review from a tertiary referral center. Bone Marrow Transplant. 2013;48:1302-7. https://doi.org/10.1038/bmt. 2013.53. 